\title{
ANALYSIS OF THERMAL AND MECHANICAL PROPERTIES OF CABLE INSULATIONS DESIGNED FOR OPERATION UNDER EMERGENCY CONDITIONS
}

\author{
PINKEROVA, M[artina] \& POLANSKY, R[adek]
}

\begin{abstract}
Paper is focused on a comparison of thermo mechanical properties of two plastic insulation materials used for cable sheaths. First measurement was analysed in the temperature range from ambient temperature to $60^{\circ} \mathrm{C}$ because of possible laying of the cables during higher temperatures than ambient temperature. Tensile strength and elongation at break were measured by universal testing machine at following temperatures: $22{ }^{\circ} \mathrm{C}$ (ambient temperature), 40, 50, 55 and 60 ${ }^{\circ} \mathrm{C}$. Results show maximum temperatures suitable for laying of the cables. The measurement of softening temperatures of sheathing materials by the thermo mechanical analysis (TMA) followed. It was determined, that recognizable change of properties is coming in the temperature interval from 60 to 100 ${ }^{\circ} \mathrm{C}$, which corresponding with the start of melting. Results from the thermo mechanical analysis in a dynamic mode (DTMA) provide also information about glass transition.
\end{abstract}

Keywords: Tensile testing, Thermomechanical analysis, Dynamic mechanical analysis, Cables sheathing, LOCA, HELB

\section{INTRODUCTION}

Contemporary trend in cables manufacture is usage of cables with special materials which cause the least damage possible in environment during fire. With increasing requirements to safety and reliability of devices also requirements to properties of used cables are increased. When the emergency situation appears cables should work reliably for time needs to ensure safety of all people and to guarantee the functionality of safety and emergency systems. Another requirement is the least burden of the environment during the manufacture, working and disposal. It is expected from used materials that they will not contribute to fire propagation (for photos of fire-testing see Fig. 1) and will not generate dense and toxic gases in case of fire. In order to declare fire characteristics of the cables it is necessary to undergo fire tests according to the valid international standards (see IEC 60331 Tests for electric cables under fire conditions, IEC 60332 Tests on electric and optical fiber cables under fire conditions, IEC 61034 Measurement of smoke density of cables burning under defined conditions, IEC 60754 Test on gases evolved during combustion of materials from cables).

Cables matching all of these requirements are generally used in areas with increased risk of the fire or increased incidence of people for example in hospitals, hotels, tunnels or nuclear power plants. These types of cables are usually marked as LFHC $=$ Low Fire Hazard Cables. [1]

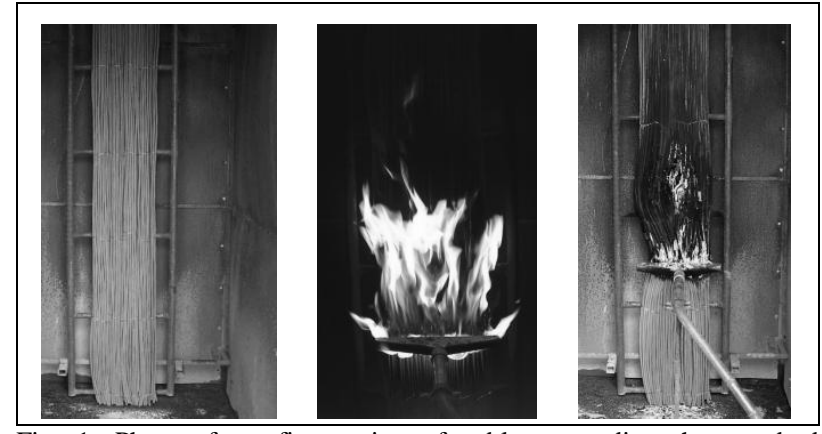

Fig. 1. Photos from fire testing of cables according the standard IEC 60331 Tests for electric cables under fire conditions

Materials used for LFHC manufacturing content not only an original polymer, but also various types of additives, for example flame retardants, stabilizers, softeners and others. Manufacturing of halogen-free and fire-retardant cables requires using of $50-65 \%$ of mineral based flame retardant (aluminium hydroxide or magnesium hydroxide) which is mixed to the compound. But this causes a significant deterioration of mechanical properties of the final product (cable).

Increased ambient temperature during operation of cables also influences the mechanical properties. Especially keeping the ordinary ambient temperature at the laying of cables is important because the cable is during laying burdened more than under common operating conditions.

Hence, the mechanical properties of insulation components of cables are influenced by ambient temperature. For this reason, the article deals with measurements of mechanical properties of sheathing materials depending on the temperature.

Although this topic is very interesting, sufficient attention has not been paid to it until now. The most occurring articles cover the topic 'thermal aging of plastic compound' $[2,3,4]$ and also 'radiation aging' [5, 6] has been discussed by several research teams in the past.

The article deals with the description and comparison of mechanical properties of two filled cable compounds. The measurement was divided to three sections. The aim of the first section was to define the temperature dependence of tensile strength and elongation at break of sheathing materials at increased temperatures $\left(20-60^{\circ} \mathrm{C}\right)$ because of possible laying of cables at these temperatures. The second measurement was intended to determine the glass transition temperature of both materials and the task 
of the third analysis was to determine the softening point of sheathing compounds.

\section{EXPERIMENTAL}

\subsection{Measured samples}

Cables used in nuclear power plants were analysed, which are designed for operation under emergency conditions. For both compounds the main polymer was used ethylene vinyl-acetate (EVA). It is copolymer of ethylene and vinyl-acetate. This material together with other additives is widely used in cable industry to sheathing of cables. [7]

The first measured material (in the article marked as LOCA) is a chemically cross-linkable filled thermoplastic mixture whose structure is formed by spatial linking the chemical bonds, which create a three dimensional net. Material is designed for cable sheathing which are used in active zone of nuclear reactor. These cables should reliably work during LOCA (Loss of Coolant Accident).

The second material is thermoplastic compound also filled by flame retardant (marked as HELB). This material is designed for cables, which can use during accident of HELB (High-energy Line Break).

Although materials have very similar composition, the internal structure is different, which is verified in the article by the results. While polymer chains of cross-linked material are linked by covalent cross bond, the thermoplastic material lacks this structure. This fact in the end influences the glass transition temperature, melting temperature and the softening point. [8]

\subsection{Measurements}

Mechanical properties were measured during the first analysis by universal testing machine LaborTech LabTest3.100 with a temperature cell (Fig. 2a). The samples were dumbbell-shaped (Fig. 2b) and were measured according to the standard EN 50363-0:2011 [9] at ambient temperature and at elevated temperatures of 40 , 50,55 and $60{ }^{\circ} \mathrm{C}$. The samples measured at increased temperatures were equilibrated 90 minutes at the certain temperature before measurement. For each testing temperature the samples were measured with a frequency 3 .

The specimen was placed in the machine between the grips and an extensometer can automatically record the change in gauge length during the test. However, this method not only records the change in length of the specimen but also all other extending / elastic components of the testing machine and its drive systems including any slipping of the specimen in the grips. Once the machine is started it begins to apply an increasing load on specimen. Throughout the tests the control system and its associated software record the load and extension of the specimen. [10]

For this analysis the load and extension of specimen were recorded. From obtained data the tensile strength and elongation at break were calculated.

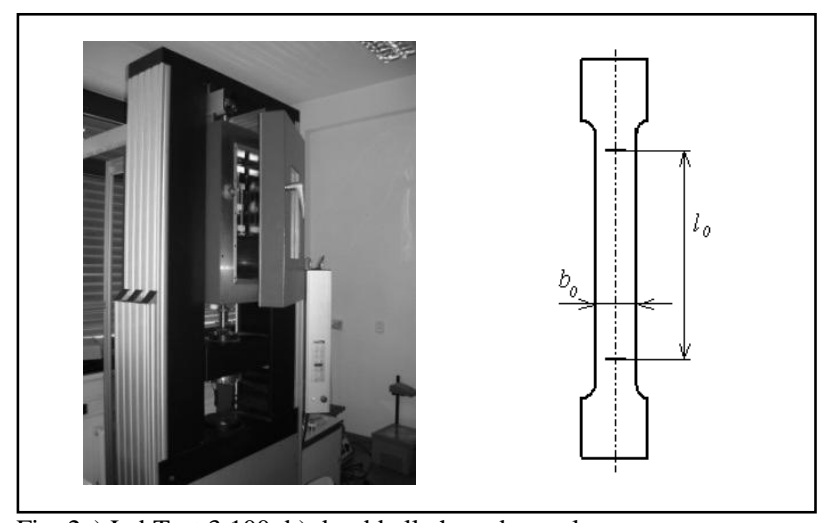

Fig. 2a) LabTest 3.100, b) dumbbell-shaped sample

During a second analysis the samples of both materials were subjected to the thermomechanical analysis in a dynamic mode (DTMA). DTMA is a technique in which the viscoelastic behaviour of the sample under oscillatory load is monitored as a function of temperature while the sample is subjected to a controlled temperature programme. It is used especially for very precise determination of glass transition temperature. DTMA was carried out on TA Instruments TMA Q400EM apparatus (Fig. 3a). The piece of cable sheath (Fig. 3b) in the shape of disk with diameter $3 \mathrm{~mm}$ was used for the analysis.

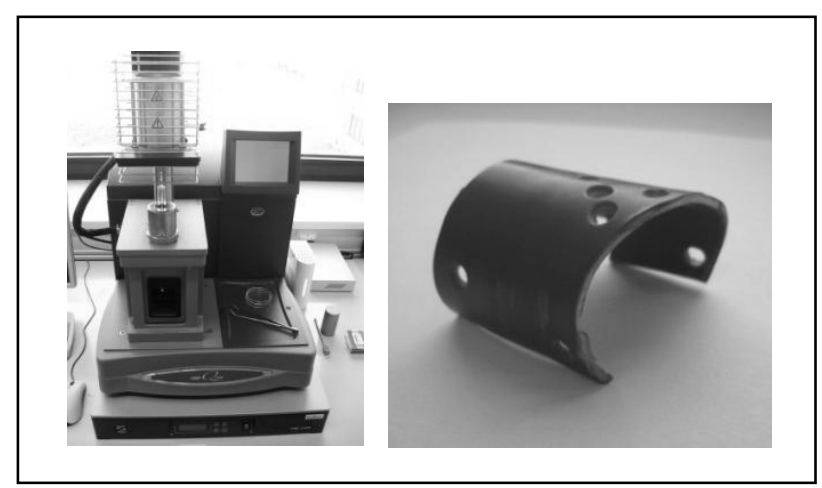

Fig. 3. a) TMA Q400EM, b) sheath of cable used for thermal analysis

The third analysis was carried out at the same apparatus (Fig. 3a); the aim of thermomechanical analysis was to determine the softening point. It is important to know the softening point of compounds for determination the temperature limits for cable manipulation. [11]

TMA measures a deformation/change of height of the sample while the sample is subjected to the constant force as a function of temperature. TMA allows to measure the changes of the sample dimensions (measurement at negligible load is named dilatometry) or to measure a penetration of a probe to a compact sample, to analysing it's softening. At this apparatus were carried out two measurements. Both were measured in the mode of penetration. Because of very fast penetration of penetration probe to the sample it was not possible to use it. That's why the expansion and macroexpansion probes with bigger contact surface were used (for illustrations of probes see Fig. 4) with a contact force $1 \mathrm{~N}$. The samples were simultaneously subjected to a linear temperature heating with a rate $5^{\circ} \mathrm{C} / \mathrm{min}$ from the ambient temperature to $100{ }^{\circ} \mathrm{C}$ in the air atmosphere. 

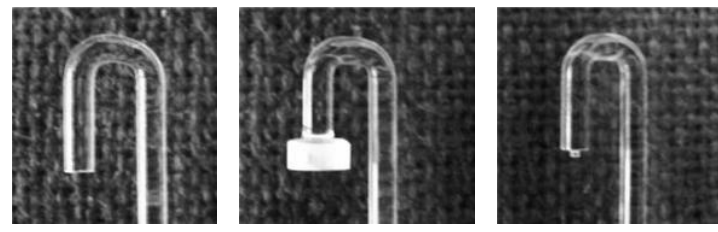

Fig. 4. Probes for TMA, from the left: expansion, macroexpansion, penetration

The arrangement of temperature furnace of the apparatus TA Instruments TMA Q400EM shows Fig. 5. In this place the sample is placed during measurement. The arrangement ensures a constant increase of temperature according to the selected temperature program.
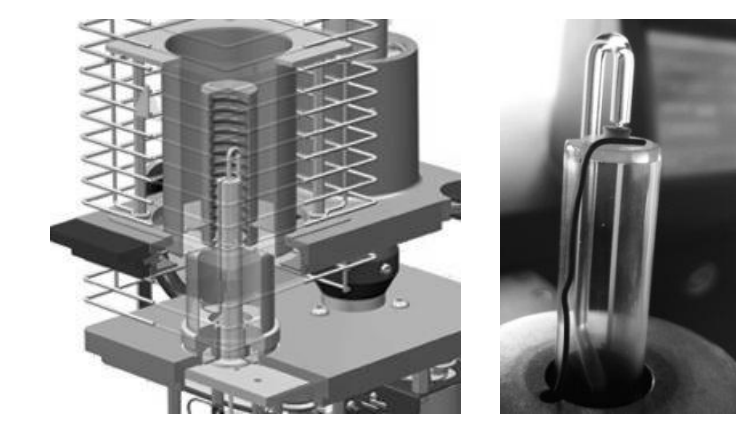

Fig. 5. a) Illustration of arrangement of temperature furnace (taken from [14]), b) Sample holder with the penetration probe on the sample and a thermocouple

The Differential Scanning Calorimetry was carried out for determining of melting points and glass transition temperature of both compounds. DSC is a thermoanalytical technique in which the difference in the amount of heat required to increase the temperature of a sample and reference is measured as a function of temperature. Both the sample and reference are maintained at nearly the same temperature throughout the experiment. Local exothermic or endothermic peaks on the curve correspond to specific temperatures during which characteristic physical-thermal effects take place. At glass transition the thermal capacity changes by a drop, so this effect is plotted as the decrease of a baseline.

Measured data were collected on a TA Instruments Q2000 (Fig. 6a) analysis. Samples ( 8,5 mg; Fig. 6b) were placed in a hermetic aluminium pans and were tested from $-70{ }^{\circ} \mathrm{C}$ to $150{ }^{\circ} \mathrm{C}$, at a temperature rate of $10^{\circ} \mathrm{C} / \mathrm{min}$ under nitrogen atmosphere.

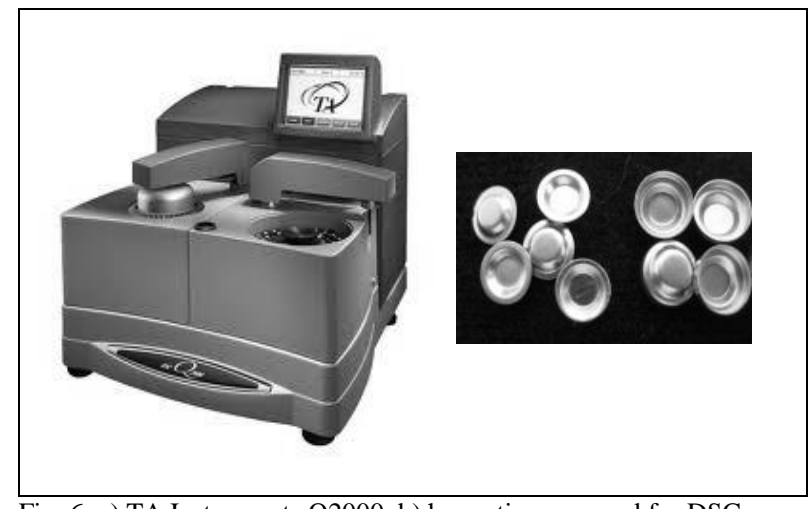

Fig. 6. a) TA Instruments Q2000, b) hermetic pans used for DSC

\section{RESULTS}

\subsection{Tensile testing}

The graphic dependence of a strain in the sample during tensile testing is shown in Fig. 7 for LOCA samples (cross-linked compound) and in Fig. 8 for HELB samples (thermoplastic compound). The curves were measured at universal testing machine with a temperature cell at various temperatures and confirm differences in internal structure of samples.

The curves of cross-linked material (LOCA) exhibits a gradually increasing dependence in contrast with thermoplastic material (HELB), where the beginning is steeper, then an obvious yield strength follows and finally the strain is almost constant. It is caused by strong bonds in the cross-linked structure of LOCA material, which for a long time resist the injurious stress. This shape of curve is a characteristic for a strong and hard materials, thereby cross-linked material of course is. [9] The second, thermoplastic compound is tough, according to the shape of the drown curves. During dragging out of sample appears after yield strength a 'neck' and material still a relatively long period of time resists of break. This area is characteristic for a plastic flow of polymer. [12]

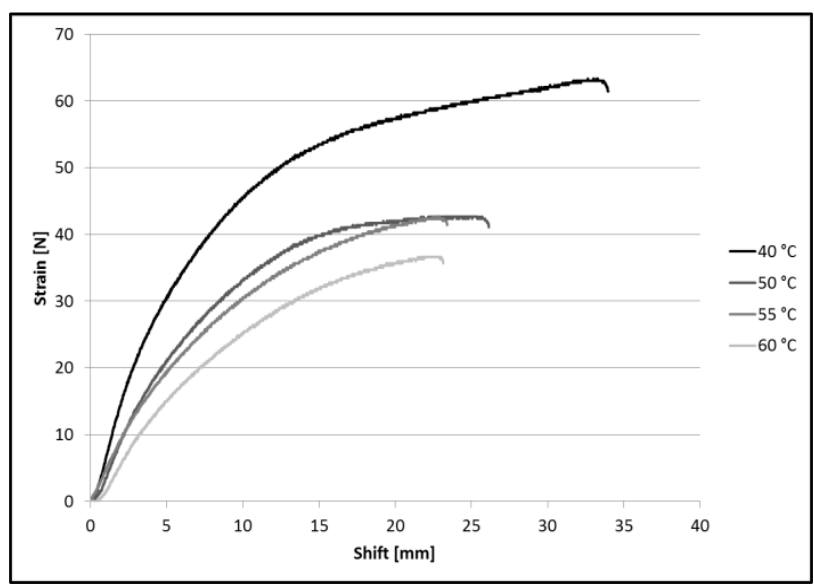

Fig. 7. Procedure of tensile testing of LOCA samples

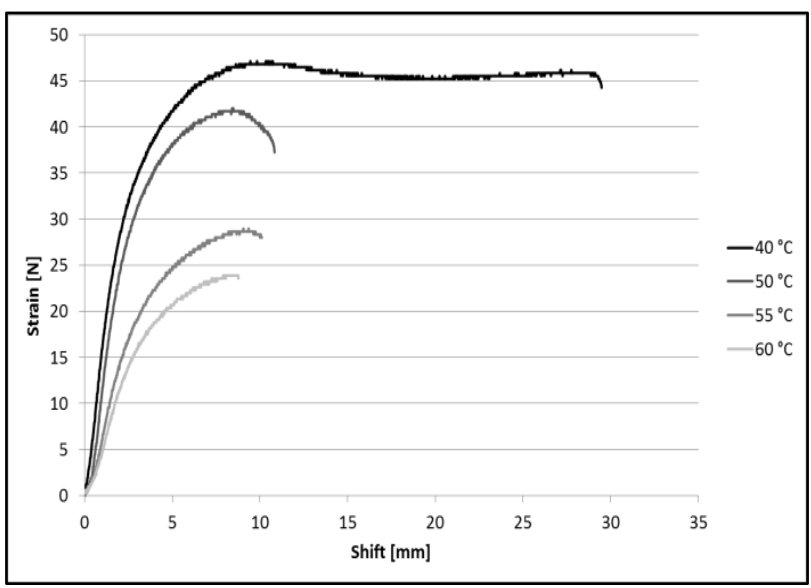

Fig. 8. Procedure of tensile testing of HELB samples

But this applies only for temperature $40^{\circ} \mathrm{C}$, at higher temperatures material breaks immediately after yield strength, which indicates a lower strength and higher 'fragility' of HELB material at these temperatures. These effects are confirmed by photos (Fig. 9) of measured 
samples which were flexed by the angle $180^{\circ}$ just after taking out from the furnace.

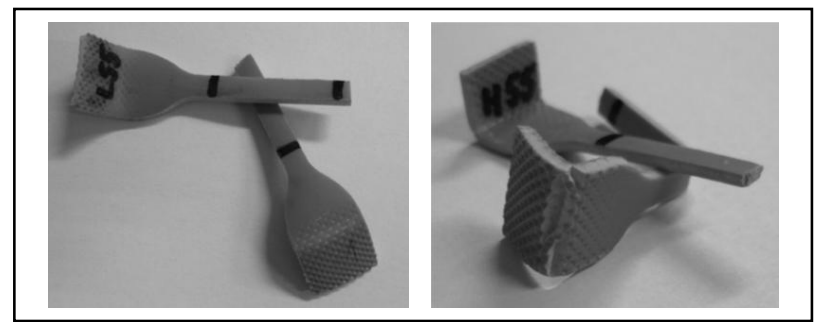

Fig. 9. Fixed samples of material LOCA (left) and HELB (right) at temperature $55^{\circ} \mathrm{C}$

Tensile strength and elongation at break were calculated from measured data and plotted to temperature dependences. Fig. 10 presents the temperature dependence of elongation at break of both compounds.

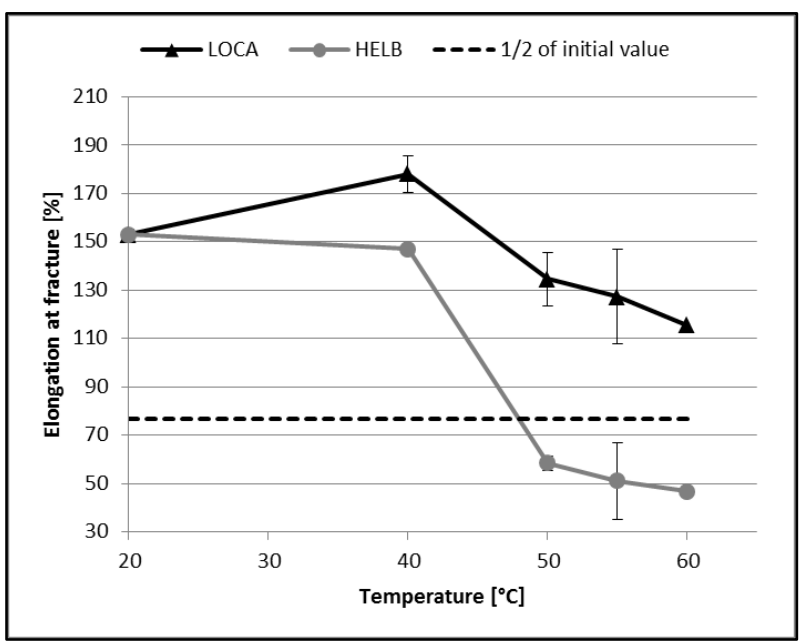

Fig. 10. Temperature dependence of Elongation at break of both materials

Values at ambient temperature are almost same $153 \%$ [7, 13]. Graph shows that elongation at break of LOCA material increases at $40{ }^{\circ} \mathrm{C}$ and then decreases up to $75 \%$ of initial value. Values are during whole temperature interval above $50 \%$ limit, so this material is applicable at these temperatures from this point of view. The $50 \%$ limit is the most frequently used acceptance criterion for LOCA cables qualification. [15]

On the other hand values of elongation at break of thermoplastic material (HELB) decreases in whole temperature interval. The first decrease is not too noticeable, but the next one is steep and at $60{ }^{\circ} \mathrm{C}$ materials amounts to only $30 \%$ of initial value of elongation at break. It follows that thermoplastic material is from this point of view applicable only to less than $50^{\circ} \mathrm{C}$.

Fig. 11 shows temperature characteristics of tensile strength of both materials. As compared to characteristics of elongation at break, these curves are more similar together. But the initial values of tensile strength at ambient temperature are different. Cross-linked material reaches $11 \mathrm{MPa}$ and the thermoplastic one $10 \mathrm{MPa}$ [7, 13]. With increasing temperature the tensile strength of both materials equally decreases. In this evaluation the same criteria was used as in the previous one. The results show that LOCA material is applicable up to $55^{\circ} \mathrm{C}$ in contrast with HELB material, which is applicable only up to $50^{\circ} \mathrm{C}$.

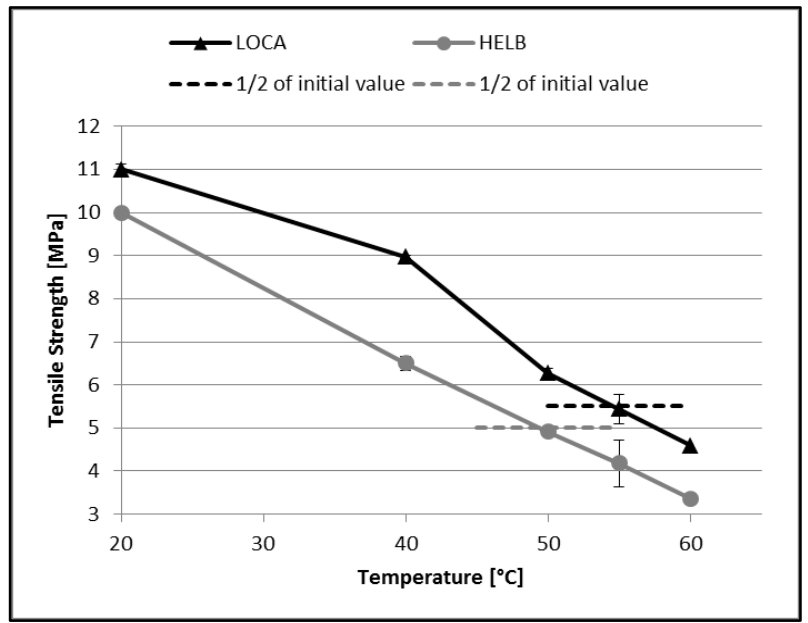

Fig. 11. Temperature dependence of Tensile Strength of both materials

\subsection{Dynamic mechanical analysis}

The second part of measurements contents dynamic mechanical analysis measured at the TMA analyser. The task of this analysis was to determine a glass transition temperature $\left(\mathrm{T}_{\mathrm{g}}\right)$ of both cable compounds. The results can be seen in Fig. 12. Dynamic mechanical analysis can to divide viscoelastic behaviour of materials to 2 components. In the picture is temperature dependence of Loss Modulus. Graph shows that the glass transition temperature of LOCA is $-32,6{ }^{\circ} \mathrm{C}$ and $\mathrm{T}_{\mathrm{g}}$ of HELB is $-25,2{ }^{\circ} \mathrm{C}$. Strong chemical bonds created in the structure of cross-linked material hold the structure to the lower temperatures then only thermoplastic structure. In this case the LOCA material is more resistant to the negative temperatures.

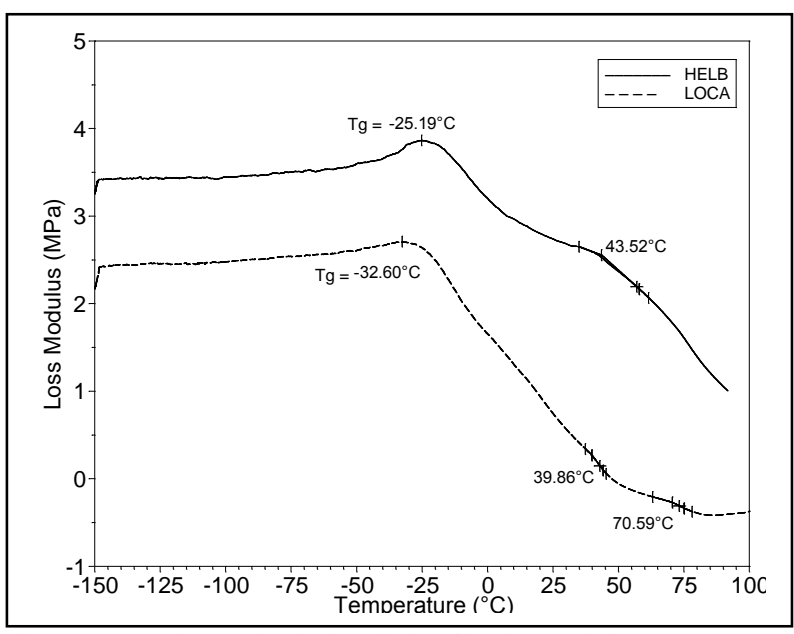

Fig. 12. Dynamic mechanical analysis of both materials

\subsection{Thermomechanical analysis}

The termomechanical analysis in penetration mode was carried out as the last one. The requirement was to widen the analysing interval of mechanical properties to $100{ }^{\circ} \mathrm{C}$. The penetration mode presents measurement with aim to push the probe to the sample. As the probe starts to penetrate to the sample, the curve at graph starts to decrease. [12] Fig. 13 shows the results of measurement with expansion probe. 
The graph shows that LOCA material is dimensionally stable up to $73,6{ }^{\circ} \mathrm{C}$, however after this temperature the curve rapidly decreases, which corresponds to softening of material (phase transition) and fast penetration of probe to the sample. In contrast HELB material changes the dimensions very slowly, which means gradual softening and penetration of probe to the sample.

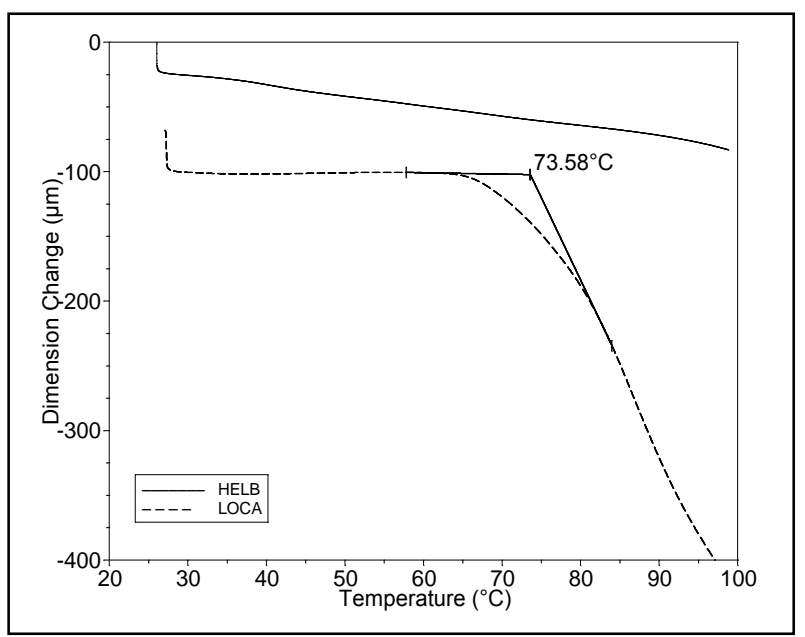

Fig. 13. Termomechanical analysis with expansion probe

The second measurement was carried out with a macroexpansion probe with a larger contact surface. The results from TMA show the similar effect, loading of constant force to LOCA sample causes at $64{ }^{\circ} \mathrm{C}$ the change of dimensions (Fig. 14), while the HELB sample stays dimensionally almost stable. It can be explained also by structure of materials. Whatever changes in the structure of cross-linked material leads to the drop at the graph. In the other hand, thermoplastic material is rather amorphous (semi-crystalline) and therefore it contents of certain amount of various large crystallites. Because of the varying size of these crystallites, they melt each in the other moment. From the general viewpoint the properties of thermoplastics change much more slowly. [16]

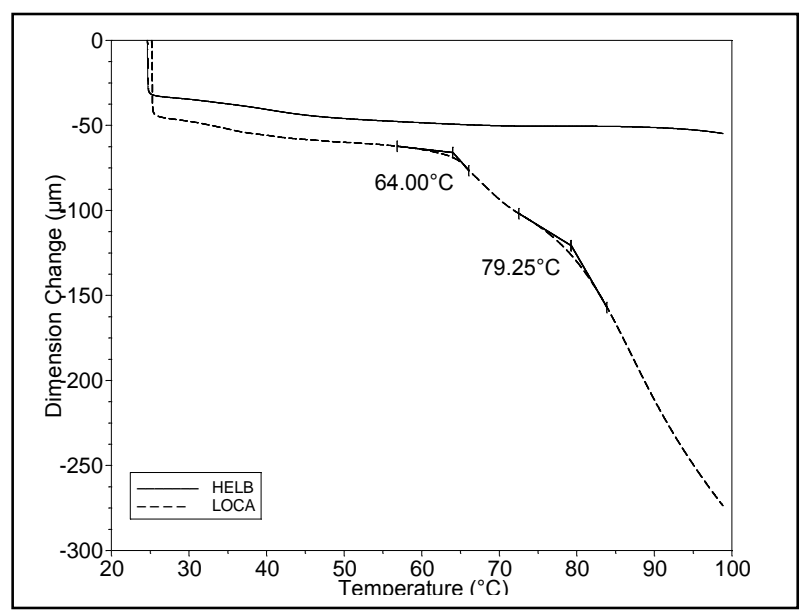

Fig. 14. Termomechanical analysis with macroexpansion probe

Fig. 14 again shows that thermoplastic material is good resistant up to $100{ }^{\circ} \mathrm{C}$, nevertheless for cross-linked material the probe penetrates to the sample near the temperature of $60^{\circ} \mathrm{C}$.

\subsection{Differential Scanning Calorimetry}

The differential scanning calorimetry was carried out as additional measurement for explanation of results from TMA. Fig. 15 and 16 show the melting temperatures of both samples (and also the glass transition temperature).

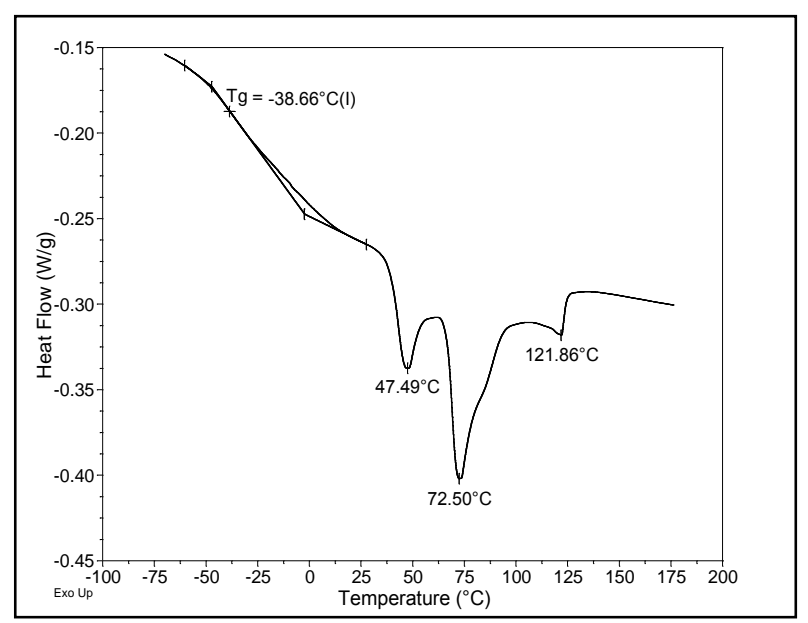

Fig. 15. Differential Scanning Calorimetry of LOCA material

Each material exhibit several endothermic peaks related to melting temperatures of single parts of semicrystalline structure, which is consisted of certain amount of various large crystalites. The amount of crystalites corresponds to a composition of polymer compound. The largest peak show temperature, at which the largest number of crystalites melt and so this melting point is the most significant for the material. Also the glass transition temperature were measured to compare with the DMA results. $\mathrm{T}_{\mathrm{g}}$ measured by DSC show slightly different result. It can be caused by different measurement techniques of DSC and DMA. However still holds that LOCA is more resistant to the negative temperatures. $\mathrm{T}_{\mathrm{g}}$ measured by DSC of LOCA is $-38,7^{\circ} \mathrm{C}$ and $\mathrm{T}_{\mathrm{g}}$ of HELB is $-30,2{ }^{\circ} \mathrm{C}$.

The measured curves confirm the results from TMA. The significant melting point in Fig. 13 corresponds with the softening point of LOCA at TMA graph (around $73^{\circ} \mathrm{C}$ ). LOCA after the reaching of this temperature starts to melt.

The largest peak of melting in Fig. 16 presents the main melting peak of HELB material. The HELB significantly melts until the temperature reaches $121,6^{\circ} \mathrm{C}$.

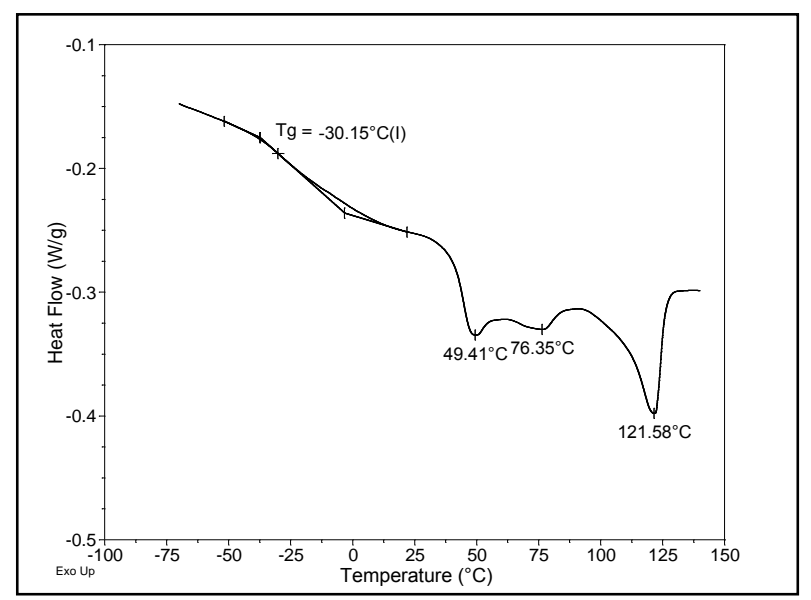

Fig. 16. Differential Scanning Calorimetry of HELB material 


\section{CONCLUSION}

Contemporary trend in cables manufacture is usage of halogen-free and fire-retardant cables which not contribute to fire propagation and not generate dense and toxic gases. Cables achieve these properties thanks to filling of mineral flame retardants. But the application of flame retardants significantly influences the mechanical properties of cable sheaths. The other cause of deterioration of mechanical properties is increased temperature of surroundings during laying of cables. For this reason several measurements were carried out and the results are following:

- In terms of elongation at break HELB is good applicable up to $40{ }^{\circ} \mathrm{C}$, than the curve steeply decreases. LOCA material elongation at break at $40{ }^{\circ} \mathrm{C}$ even slightly increases and then it decreases too. But the LOCA is applicable through whole measured temperature interval.

- Tensile strength of HELB plotted the curve which steeper decreases than LOCA dependence. HELB is applicable up to $50{ }^{\circ} \mathrm{C}$ and LOCA up to $55^{\circ} \mathrm{C}$. The graphic dependences of a strain in the sample during tensile testing (Fig. 5,6) confirm differences in inert structure of both materials. HELB presents a tough material with yield strength, which corresponds with a thermoplastic material, whereas LOCA material is without yield strength. This fact confirms also photos in Fig. 7.

- DTMA was applied to measure the glass transition temperature. The higher resistance against negative temperatures proved LOCA $\left(\mathrm{T}_{\mathrm{g}}=-32{ }^{\circ} \mathrm{C}\right) . \mathrm{T}_{\mathrm{g}}$ of HELB is $-25^{\circ} \mathrm{C}$.

- $\quad$ TMA presents HELB as a very resistant material to a constant force at increasing temperature. LOCA shows better stability with expansion probe than HELB, but only up to $73,6{ }^{\circ} \mathrm{C}$. Then the curve steeply decreases. In contrast to this, HELB changes the dimensions slowly and from $73,6{ }^{\circ} \mathrm{C}$ presents better dimensional stability than LOCA. At measurement with macroexpansion probe the curve of LOCA decreases after temperature reaches $64^{\circ} \mathrm{C}$.

- $\quad$ DSC confirms all results from DTMA and TMA. The melting points and glass transition temperatures of both compounds were analysed via DSC.

The results show that from laying at increased temperatures point of view, the LOCA is more resistant material, but after temperature reaches $73{ }^{\circ} \mathrm{C}$, the melting appears. For laying of cables at ambient temperature, HELB is good and then without larger mechanical stress this material keeps good mechanical properties up to the temperature $121,6^{\circ} \mathrm{C}$.

It is important to specify the laying temperature for each cable, because else it can cause a lot of problems. For future measurement I would recommend to focus on measurement of various mechanical properties at increased temperatures, not only measure of mechanical properties after thermal ageing of cable samples.

\section{ACKNOWLEDGEMENTS}

This research has been supported by the Student Grant Agency of the West Bohemia University in Pilsen, grant No. SGS-2012-026 "Material and Technology Systems in Electrical Engineering" and by European Regional Development Fund and the Ministry of Education, Youth and Sports of the Czech Republic under the Regional Innovation Centre for Electrical Engineering (RICE), project No. CZ.1.05/2.1.00/03.0094.

\section{REFERENCES}

[1] Lu, S. \& Hamerton, I. (2002). Recent developments in the chemistry of halogen-free flame retardant polymers. Progress in Polymer Science. Vol. 27, No. 8, 2002, pp. 1661-1712

[2] Mecheri, Y.; Boukezzi, L.; Boubakeur, A. \& Lallouani, M. (2000). Dielectric and mechanical behavior of cross-linked polyethylene under thermal aging. Proceedings of Conference on Electrical Insulation and Dielectric Phenomena, October 15-18, 2000, Victoria, Canada, ISBN 0-7803-6413-9, pp. 560-563

[3] Bartoníček, B., Hnát, V. \& Plaček, V. Life-assessment technique for nuclear power plant cables. Radiation Physics and Chemistry, Vol. 52, No. 1-6, 998, pp. 639-642. ISSN 0969806x

[4] Chailan, J.-F., Chauchard, J., Seytre, G., Boiteux, G., Escoubes, M. \& Pinel, B. Effects of radiation and thermal ageing on physicochemical properties of elastomeric materials (EPR-CSPE) for cable insulation and sheathing. Proceedings of Sixth International Conference on Dielectric Materials, Measurements, and Applications, 7-10 September 1992, University of Manchester Institute of Science and Technology Conference Center, Manchester, UK. 1992. ISBN 0-85296-551-6

[5] Plaček, V. \& Kohout, T. Comparison of cable ageing. Radiation Physics and Chemistry. Vol. 79, No. 3, 2010, pp. 371-374. ISSN 0969806x

[6] Bartoníček, B., Plaček, V. \& Hnát, V.. Comparison of degradation effects induced by gamma radiation and electron beam radiation in two cable jacketing materials. Radiation Physics and Chemistry. Vol. 76, No. 5, 2007, pp. 857-863. ISSN 0969806x

[7] Cárdenas, M.A., García-López, D., Gobernado-Mitre, I., Merino, J. C., Pastor,J. M., Martínez, J. De D., Barbeta, J. \& Calveras, D.. Mechanical and fire retardant properties of EVA/clay/ATH nanocomposites. Effect of particle size and surface treatment of ATH filler. Polymer Degradation and Stability. Vol. 93, No. 11, 2008 pp. 2032-2037. ISSN 01413910

[8] Reyes-Labarta, J.A., Olaya, M.M. \& Marcilla, A. DSC and TGA study of the transitions involved in the thermal treatment of binary mixtures of PE and EVA copolymer with a crosslinking agent. Polymer. Vol. 47, No. 24, 2006, pp. 8194-8202. ISSN 00323861

[9] European Standard EN 50363-0:2011. Insulating, sheathing and covering materials for low-voltage energy cables. 2006

[10] Springer handbook of materials measurement methods. 1th ed. New York: Springer, 2006, xxvi, 1208 p. ISBN 35-402-0785-6

[11]Vaníček, J. Metody termické analýzy: Termická gravimetrie a termická mechanická analýza. pp. 3-4. Available from http://www.ft.vsl ib.cz/depart/ktm/files/20060106/prednaska6.pdf

[12]Ehrenstein, Gottfried W. Thermal analysis of plastics: theory and practice. Munich: Hanser, 2004, 368 s. ISBN 34-462-2673-7

[13]Liangyu, G., Qing, W. \& Jiang, Ch. Study On Cross-linked Polyolefine Sheath Material for FIR Cable. IEEE electrical insulation magazine: a publication of the IEEE Electrical Insulation Society. pp. 884-887. ISSN 0883-7554

[14] Ta Instruments: Our products. TA INSTRUMENTS. 2012 Available from: http://www.tainstruments.cz/product.aspx?id= $198 \& n=1 \&$ siteid $=11$

[15]Plaček, V., Kohout, T., Kábrt, J. \& Jiran, J. The influence of mechanical stress on cable service life-time. Polymer Testing. Vol. 30, No. 7, 2011, pp. 709-715. ISSN 01429418

[16]Lenfeld, P. Technologie II, Zpracování plastů: Plasty a jejich zpracovatelské vlastnosti. Available from: http://www.ksp.tul.cz/cz /kpt/obsah/vyuka/skripta_tkp/sekce_plasty/obsah_plasty.htm 